\title{
Bolton ratio in subjects with normal occlusion and malocclusion
}

\author{
Ivan Delgado Ricci', Marco Antonio Scanavini', Armando Koichiro Kaieda', \\ Henrique Damian Rosário ${ }^{2}$, Luiz Renato Paranhos ${ }^{3}$ \\ 'Department of Orthodontics, Methodist University of São Paulo, São Bernardo do Campo, SP, Brazil \\ ${ }^{2}$ Department of Oral Biology, Sacred Heart University, Bauru, SP, Brazil \\ ${ }^{3}$ Department of Orthodontics, School of Dentistry, Federal University of Sergipe, Lagarto, SE, Brazil
}

\begin{abstract}
Aim: To verify the presence of Bolton anterior and total discrepancy in Brazilian individuals with natural normal occlusion and Angle's Class I and Class II, division 1 malocclusions. Methods: The sample was divided in three groups ( $n=35$ each): natural normal occlusion; Class I malocclusion; Class II, division 1 malocclusion. Of the 105 Caucasian Brazilian individuals, 24 were boys and 81 were girls aged from 13 to 17 years and 4 months. The mesiodistal width of the maxillary and mandibular teeth, from the left first molar to the right first molar, was measured on each pre-treatment dental plaster cast using a digital caliper accurate to $0.01 \mathrm{~mm}$ resolution. Values were tabulated and the Bolton ratio was applied. The Kolmogorov-Smirnov test was used to verify if data were normally distributed $(p>0.2)$. For comparison between the values obtained and those from the Bolton standard, Student's $t$ test was used and one-way ANOVA was used for comparisons among the 3 groups, with a significance level of $5 \%(p<0.05)$. Results: For groups 1,2 and 3, respectively, the total ratio found was $90.36 \%$ (SD 1.70), 91.17\% (SD \pm 2.58 ) and $90.76 \%$ (SD \pm 2.45 ); and the anterior ratio was $77.73 \%$ (SD 2.39), $78.01 \%$ (SD 2.66) and $77.30 \%$ (SD 2.65). Conclusions: There was no significant difference among the groups regarding the values indicated in the Bolton ratio.
\end{abstract}

Keywords: malocclusion, Angle class I, malocclusion, Angle class II, tooth abnormalities.

\section{Introduction}

A detailed planning phase is critical to the success of orthodontic treatment, by which the professional may identify and prevent occlusal disorders that impede treatment completion ${ }^{1,2}$. In addition, in this stage tooth discrepancies have greater influence. Anatomical changes in dental proportions preclude obtaining an balanced occlusion with good intercuspation, as well as appropriate overjet and overbite $^{3}$. According to Proffit ${ }^{4}$, although natural teeth have a good ratio in most individuals, part of the population (5\%) has some degree disproportion in tooth size. Freeman et al. ${ }^{5}$ found that the excess of mass is greater in the mandible $(19.7 \%)$ than in the maxilla $(10.8 \%)$.

In the beginning of the last century, Black became interested in the study of Correspondence to: Luiz Renato Paranhos Departmento de Ortodontia Universidade Federal de Sergipe Rua Pe Alvares Pirangueira, 248, CEP: 49400-000, Centro, Lagarto, SE, Brasil

Phone: +55 19983367619

Fax: +551938044002

E-mail: paranhos@ortodontista.com.br dental morphology and size ${ }^{6}$. Among the numerous analyses used by orthodontists, the study of casts allows to verify the existence and severity of interarch dental discrepancy ${ }^{7,8}$. The Bolton analysis ${ }^{2}$ came up with the proposal to locate and determine tooth size discrepancies - intra and intermaxillary - thus avoiding the need to perform set up for such purpose. The Bolton method assists in the decision to perform interdental stripping, dental extractions, or even increase of dental crown with restorative material. 
Although several studies ${ }^{3,9-17}$ investigated the difference in the incidence of the Bolton discrepancy between genders, there are still conflicting results in the literature. Another relevant question is the relationship between the Bolton ratio and the various types of malocclusion ${ }^{17,712,14-18}$. Again, although there is evidence in the literature ${ }^{11,12,15-17,19,20}$ on the prevalence of the Bolton discrepancy in diverse populations, there is no consensus about its relationship with the different types of malocclusions classified by Angle. Given the importance of these topics, this study aimed to evaluate the presence of the Bolton anterior and total discrepancy in individuals with natural normal occlusion, Class I and Class II, division 1 malocclusions. Additionatly, it was investigated whether there was influence of sexual dimorphism on the obtained values.

\section{Material and methods}

\section{Sample}

This study was undertaken after approval by the Ethics Committee of the Methodist University of São Paulo (UMESP), Brazil, under registration number \#296120-09. The sample consisted of 105 pairs of plaster casts as part of the orthodontic records of UMESP, corresponding to Caucasian Brazilian patients, with a minimum age of 13 years and maximum age of 17 years and 4 months (mean age: 15 years and 2 months), who presented teeth with intact proximal surfaces and centric relation near the habitual position. The sample exclusion criteria were: previous orthodontic treatment, agenesis and dental extractions. The sample was divided into three groups: Group $1(\mathrm{n}=35)$ with natural normal occlusion; Group 2 $(\mathrm{n}=35)$ with Angle's Class I malocclusion; and Group 3 $(\mathrm{n}=35)$ with Angle's Class II, division 1 malocclusion.

\section{Measurement of the plaster casts}

The greatest mesiodistal distance was measured in each tooth in the maxillary and mandibular arches (except for $2^{\text {nd }}$ and $3^{\text {rd }}$ molars) using a Mitutoyo digital caliper (model 500144, Suzano, SP, Brazil), with capacity of $150 \mathrm{~mm}$ and accurate to $0.01 \mathrm{~mm}$. A previously trained single operator performed the procedures maintaining carefully the models and the caliper parallel to the ground. When the measurement of an arch was finished, the caliper was closed and zeroed again. Its continued use could implicate errors due to the total closure of the instrument, and sometimes the display did not indicate zero. Such procedure provided the method a greater accuracy.

In order to evaluate the intraexaminer's method error (Table 1), measurements were taken twice at an interval of

Table 1. Mean and standard deviation of two measurements, paired t-test and Dahlberg's error used to assess the systematic and random error.

\begin{tabular}{|c|c|c|c|c|c|c|c|}
\hline \multirow[t]{2}{*}{ Tooth } & \multicolumn{2}{|c|}{$1^{\text {st }}$ Measurement } & \multicolumn{2}{|c|}{$2^{\text {nd }}$ Measurement } & \multirow[t]{2}{*}{$\mathrm{t}$} & \multirow[t]{2}{*}{$p$} & \multirow[t]{2}{*}{ Errol } \\
\hline & Mean & SD & Mean & SD & & & \\
\hline 16 & 10.45 & 0.50 & 10.36 & 0.52 & 2.069 & $0.052 \mathrm{~ns}$ & 0.15 \\
\hline 15 & 6.88 & 0.49 & 6.80 & 0.44 & 2.882 & $0.009^{*}$ & 0.10 \\
\hline 14 & 7.23 & 0.47 & 7.08 & 0.49 & 4.595 & $0.000^{*}$ & 0.15 \\
\hline 13 & 7.92 & 0.48 & 7.90 & 0.46 & 0.410 & $0.686 \mathrm{~ns}$ & 0.10 \\
\hline 12 & 7.09 & 0.60 & 7.02 & 0.59 & 3.147 & $0.005^{\star}$ & 0.09 \\
\hline 11 & 8.85 & 0.52 & 8.83 & 0.51 & 0.561 & $0.581 \mathrm{~ns}$ & 0.09 \\
\hline 21 & 8.86 & 0.53 & 8.80 & 0.54 & 2.026 & $0.056 \mathrm{~ns}$ & 0.11 \\
\hline 22 & 7.01 & 0.54 & 6.96 & 0.57 & 1.285 & $0.214 \mathrm{~ns}$ & 0.12 \\
\hline 23 & 7.91 & 0.43 & 7.73 & 0.53 & 3.462 & $0.002^{*}$ & 0.22 \\
\hline 24 & 7.32 & 0.49 & 7.22 & 0.46 & 2.371 & $0.028^{*}$ & 0.14 \\
\hline 25 & 6.91 & 0.53 & 6.83 & 0.52 & 3.003 & $0.007^{*}$ & 0.10 \\
\hline 26 & 10.46 & 0.50 & 10.38 & 0.51 & 2.990 & $0.007^{*}$ & 0.09 \\
\hline 36 & 10.98 & 0.62 & 10.93 & 0.60 & 2.263 & $0.035^{\star}$ & 0.09 \\
\hline 35 & 7.22 & 0.47 & 7.17 & 0.46 & 1.518 & $0.145 \mathrm{~ns}$ & 0.13 \\
\hline 34 & 7.20 & 0.41 & 7.12 & 0.40 & 3.297 & $0.004^{*}$ & 0.09 \\
\hline 33 & 6.96 & 0.41 & 6.85 & 0.42 & 4.875 & $0.000^{*}$ & 0.10 \\
\hline 32 & 6.04 & 0.41 & 6.04 & 0.40 & 0.096 & $0.925 \mathrm{~ns}$ & 0.14 \\
\hline 31 & 5.49 & 0.34 & 5.50 & 0.33 & 0.313 & $0.758 \mathrm{~ns}$ & 0.13 \\
\hline 41 & 5.54 & 0.36 & 5.54 & 0.36 & 0.051 & $0.960 \mathrm{~ns}$ & 0.09 \\
\hline 42 & 6.00 & 0.38 & 5.98 & 0.45 & 0.425 & $0.675 \mathrm{~ns}$ & 0.14 \\
\hline 43 & 6.79 & 0.42 & 6.72 & 0.42 & 1.564 & $0.133 \mathrm{~ns}$ & 0.15 \\
\hline 44 & 7.22 & 0.42 & 7.17 & 0.45 & 2.153 & $0.044^{*}$ & 0.10 \\
\hline 45 & 7.31 & 0.50 & 7.23 & 0.53 & 3.249 & $0.004^{*}$ & 0.10 \\
\hline 46 & 10.95 & 0.53 & 10.92 & 0.56 & 0.988 & $0.335 \mathrm{~ns}$ & 0.10 \\
\hline $16-26$ & 96.88 & 4.70 & 95.92 & 4.77 & 5.603 & $0.000^{*}$ & 0.87 \\
\hline $13-23$ & 47.64 & 2.63 & 47.24 & 2.73 & 3.965 & $0.001^{*}$ & 0.42 \\
\hline $36-46$ & 87.70 & 3.92 & 87.16 & 4.00 & 3.483 & $0.002^{*}$ & 0.62 \\
\hline $33-43$ & 36.81 & 1.91 & 36.64 & 1.97 & 1.306 & $0.207 \mathrm{~ns}$ & 0.45 \\
\hline Bolton's Total & 90.56 & 1.60 & 90.90 & 1.86 & 2.433 & $0.024^{*}$ & 0.51 \\
\hline Bolton's Anterior & 77.32 & 2.24 & 77.59 & 2.18 & 1.401 & $0.177 \mathrm{~ns}$ & 0.65 \\
\hline
\end{tabular}

${ }^{*}$ statistically significant difference $(p<0.05)$. ns=not statistically significant difference 
Table 2. Anterior and total ratio analyzed according to gender and malocclusion (Student's t test).

\begin{tabular}{lllllllc}
\hline Group & Variable & $\begin{array}{l}\text { Female } \\
\text { Mean }\end{array}$ & SD & Mean & SD & t & p \\
& & 90.36 & 1.70 & 90.44 & 1.20 & -0.132 & $0.896 \mathrm{~ns}$ \\
Normal & BoltonTotal & 77.73 & 2.39 & 76.68 & 1.19 & 1.195 & $0.241 \mathrm{~ns}$ \\
& Bolton Anterior & 91.17 & 2.58 & 91.25 & 3.24 & -0.068 & $0.946 \mathrm{~ns}$ \\
Class I & BoltonTotal & 78.01 & 2.66 & 78.66 & 3.64 & -0.561 & $0.579 \mathrm{~ns}$ \\
& Bolton Anterior & 90.76 & 2.45 & 90.37 & 2.35 & 0.405 & $0.688 \mathrm{~ns}$ \\
Class II & BoltonTotal & 90.35 & & & & \\
& Bolton Anterior & 77.30 & 2.65 & 77.27 & 2.08 & 0.029 & $0.977 \mathrm{~ns}$ \\
\hline
\end{tabular}

ns=not statistically significant difference

15 days by randomly selecting $20 \%$ of the 105 pairs of plaster casts $(n=21)$, resulting in 7 pairs per group. For suc purpose, the paired $t$ test was used with a significance level of $5 \%$. For determining the random error, the calculation error proposed by Dahlberg ${ }^{21}$ was applied. To verify if data were normally distributed, was used the Kolmogorov-Smirnov test $(p>0.2)$. For comparison between genders and obtained values, and those from the Bolton standard, was used the Student's t test. One-way ANOVA was used for comparisons among the 3 groups, with a significance level of $5 \%(\mathrm{p}<0.05)$.

\section{Results}

There was no statistically significant difference between genders for both anterior and total ratio in each group (Table 2). Since no occurrence of gender dimorphism was found, the sample was grouped so that it could be possible to compare a potential relationship between natural normal occlusion and the different types of malocclusion (Class I and Class II, division 1). The presence or not of tooth size discrepancy was also verified.

Table 3 shows that there was no statistically significant difference for anterior and total ratio among the three studied groups.

Table 3. Comparison between the Bolton anterior and total ratio among the three groups $(\mathrm{n}=35$ each).

\begin{tabular}{lllll}
\hline Group & \multicolumn{2}{c}{ Bolton Total } & \multicolumn{2}{c}{ Bolton Anterior } \\
& Mean & SD & Mean & SD \\
Normal & 90.38 & 1.58 & 77.49 & 2.20 \\
Class I & 91.19 & 2.70 & 78.16 & 2.87 \\
Class II & 90.67 & 2.40 & 77.29 & 2.51 \\
\hline ANOVA (p value) & $0.324 \mathrm{~ns}$ & $0.331 \mathrm{~ns}$ \\
\hline
\end{tabular}

ns=not statistically significant difference
When the groups were compared in relation to the Bolton standard (Table 4), no statistically significant difference could be found for the anterior and total ratio, except for the total ratio of the normal occlusion group, and the anterior ratio of the Class I malocclusion group.

\section{Discussion}

The diagnosis of dental discrepancies has been proven to be of great importance in planning orthodontic treatments. According to Bolton ${ }^{2}$, a good occlusion depends on a correct ratio between the dental masses in the maxillary and mandibular arches. By measuring the greatest mesiodistal width of each permanent tooth, including all the teeth since the $1^{\text {st }}$ left to the $1^{\text {st }}$ right permanent molar, this author ${ }^{2}$ found a ratio of $91.3 \%$ (SD 1.91). When only the six anterior teeth of the arch were evaluated, the ratio was $77.2 \%$ (SD 1.65). For Bolton ${ }^{2}$, patients with means of anterior and total tooth size ratio above or below $2 \%$ of the values established in his research, should be classified as having tooth size discrepancy. Other authors $5,8,12,19,22,23$ agree that such dental relationship is mandatory for the orthodontic planning and finishing, in addition to influencing on occlusal factors. The significant values that were applied in this research for tooth size discrepancy followed the Bolton criterion. Nonetheless, the Bolton's sample consisted only of Class I individuals, without gender differentiation. Similar methodology was used in other studies ${ }^{1,3,5,9,10,14-18,20,24,25}$.

It is worth noting that the plaster casts in the sample came from Brazilians, which reflects multiethnicity and consequent genetic variety. Individuals carry peculiarities and genetic features from their parents, such as teeth size and shape $\mathrm{e}^{1,26,27}$. In a study with homo- and heterozygous twins,

Table 4. Anterior and total ratio $(n=35)$ compared with the Bolton ratio $(\mathrm{n}=55)$ (Student's t test).

\begin{tabular}{llllllll}
\hline Bolton & Group & \multicolumn{2}{c}{ Obtained } & \multicolumn{2}{c}{ Standard } & t & p \\
\cline { 3 - 6 } Total & & Mean & SD & Mean & SD & & \\
& Normal & 90.38 & 1.58 & 91.30 & 1.91 & 2.386 & $0.019^{*}$ \\
& Class I & 91.19 & 2.70 & 91.30 & 1.91 & 0.232 & $0.817 \mathrm{~ns}$ \\
\multirow{4}{*}{ Anterior } & Class II & 90.67 & 2.40 & 91.30 & 1.91 & 1.377 & $0.172 \mathrm{~ns}$ \\
& Normal & 77.49 & 2.20 & 77.20 & 1.65 & 0.714 & $0.477 \mathrm{~ns}$ \\
& Class I & 78.16 & 2.87 & 77.20 & 1.65 & 2.009 & $0.048^{*}$ \\
& Class II & 77.29 & 2.51 & 77.20 & 1.65 & 0.204 & $0.839 \mathrm{~ns}$ \\
\hline
\end{tabular}

* - statistically significant difference $(p<0.05)$. ns=not statistically significant difference 
it was concluded that the mesiodistal width of the teeth and the anterior tooth ratio are genetically influenced ${ }^{27}$. Another study $^{3}$ reported a marked difference between the studied Brazilian population and the Bolton's sample, probably owing to the extensive miscegenation of the population in Brazil. In the present study, however, the studied population showed values for total and anterior ratio very close to those proposed by Bolton, thus allowing his table to be used, even though his values were based on a North American Caucasian population $^{18}$. The literature ${ }^{5,12,26,28,29}$ reported significant differences between races, both for dental size and proportions.

There are reports in the literature ${ }^{5,12,26,28,29}$ indicating a trend of men presenting teeth greater than those of women concerning the mediodistal width. These findings stimulated one of the aims of this research, which was to determine if there is sexual dimorphism in the different types of malocclusion in relation to tooth size discrepancy. Since there was none, the groups had to be categorized by gender.

In the group with natural normal occlusion, the observed values were similar regarding the means obtained for the total ratio in females $(90.36 \%)$ and males $(90.44 \%)$. In addition, close values were also found for the anterior ratio $-77.73 \%$ and $76.68 \%$ respectively. Similar results were obtained by several authors ${ }^{1,9,12,14,30}$. The only measure that was shown to be increased in females was the amount of crowding in the lower anterior region (observed during measurement), although with no statistical significance. Uysal et al. ${ }^{18}$ found sexual dimorphism in patients with normal occlusion only for the total ratio $(91.73 \%$ in women and $89.83 \%$ in men). The authors ${ }^{18}$ point out that this difference may be related to features of the studied population, and that different racial groups should be treated according to their own characteristics. Smith et al. ${ }^{28}$ corroborate the presence of sexual dimorphism among genders and races with respect to the parameters proposed by Bolton.

Sexual dimorphism was not found in Class I and II malocclusions, with similar means obtained for the total ratio in males $(91.17 \%)$ and females $(91.25 \%)$. Similarly, close values were also found between the means for the anterior ratio $-78.01 \%$ and $78.66 \%$ respectively for Class I. With regards to the Class II, division 1 group, the results were $90.76 \%$ and $90.37 \%$, for males and females respectively. An approximate value between means was also found for the anterior ratio $-77.30 \%$ and $77.27 \%$ respectively. These results are similar to those of several authors ${ }^{5,17,18,24}$. It is likely that racial variation between samples explains the differences between studies ${ }^{1,3,18}$.

Regarding the Bolton ratio, there was no significant difference between the groups, i.e., the means obtained for this measure in individuals with natural normal occlusion, Class I and Class II, division 1 were very close, indicating that the relationship between all the maxillary and mandibular teeth does not influence the occurrence of malocclusions. However, it is important to point out that the selection criterion for the type of malocclusion used here was proposed by Angle, which takes into account only the mesiodistal relationship between the maxillary and mandibular first molars, excluding facial sagittal and vertical discrepancies that may be masked by dental compensations.

Other studies have found similar results ${ }^{1,12,14,15,17}$. Yet, Oktay and Ulukaya ${ }^{30}$ identified differences only for the posterior region. In the samples of Fattahi et al. ${ }^{24}$ and Alkofide and Hashim ${ }^{14}$ there was a higher incidence of the Bolton discrepancy in individuals with Class III malocclusion. However, when only the anterior region was analyzed, there was a higher incidence of discrepancy for Class III, but only when compared to Class $\mathrm{II}^{14}$. Motta et al. ${ }^{11}$ obtained opposite results, reporting a higher incidence in individuals with Class I and II malocclusions. On the other hand, based on a sample of 300 Brazilians, Araujo and Souki $^{3}$ reported an increased incidence in Class I and III patients. Only when the anterior region was analyzed, Class III subjects had a higher incidence of discrepancy.

The comparison of the Bolton tooth ratio between normal occlusion and Class I and Class II, division 1 malocclusions, showed no significant differences. There was no sexual dimorphism among tooth size discrepancies when compared with the natural normal occlusion and the different types of malocclusions investigated.

\section{References}

1. Akyalçin S, Dogan S, Dinçer B, Erdinc AME, Öncag G. Bolton tooth size discrepancies in skeletal class I individuals presenting with different dental Angle classifications. Angle Orthod. 2006; 76: 637-43.

2. Bolton WA. Disharmony in tooth size and its relations to the analysis and treatment of malocclusion. Angle Orthod. 1958; 28: 113-30.

3. Araujo E, Souki M. Bolton anterior tooth size discrepancies among different malocclusion groups. Angle Orthod. 2003; 73: 307-13.

4. Proffit WR. Contemporary orthodontics, 4th edn. St Louis: Elsevier; 2007.

5. Freeman JE, Maskeroni AJ, Lorton, L. Frequency of Bolton tooth size discrepancies among orthodontic patients. Am J Orthod Dentofacial Orthop. 1996; 11:24-7.

6. Harris FE, Burris GB. Contemporary permanent tooth dimensions, with comparisons to G.V. Blacks data. J Tenn Dent Assoc. 2003; 83: 25-9.

7. Al-Khateeb SN, Alhaija ESJA. Tooth Size Discrepancies and Arch Parameters among Different Malocclusions in a Jordanian Sample. Angle Orthod. 2006; 76: 459-65.

8. Al-Omari IK, Al-Bitar ZB, Hamdan AM. Tooth Size Discrepancies Among Jordanian schoolchildren. Eur J Orthod. 2008; 30: 527-31.

9. Johe RS, Steinhart T, Sado N, Greenberg B, Jing S. Intermaxillary toothsize discrepancies in different sexes, malocclusion groups, and ethnicities. Am J Orthod Dentofacial Orthop. 2010; 138: 599-607.

10. Bernabé E, Villanueva KM, Flores-Mir, C. Tooth width ratios in crowded and noncrowded dentitions. Angle Orthod. 2004; 74: 765-8.

11. Motta ATS, Rodrigues S, Quintão CCA, Capelli Jr. J. Analysis of tooth size discrepancy in patients of Rio de Janeiro State University Orthodontic Clinic. Dental Press J Orthod. 2004; 9: 83-90.

12. O'Mahony G, Millett DT, Barry MK, McIntyre GT, Cronin MS. Tooth size discrepancies in Irish orthodontic patients among different malocclusion groups. Angle Orthod. 2011; 81: 130-4.

13. Alkofide $\mathrm{E}$, Hashim $\mathrm{H}$. Intermaxillary tooth size discrepancies among different malocclusion classes: a comparative study. J Clin Pediatr Dent. 2002; 26: 383-7.

14. Basaran G, Selek M, Hamamci O, Akkus Z. Intermaxillary Bolton tooth size discrepancies among different malocclusion groups. Angle Orthod. 2006; 76: 26-30 
15. Kumar $P$, Singh $V$, Kumar $P$, Sharma $P$, Sharma R. Effects of premolar extractions on Bolton overall ratios and tooth-size discrepancies in a north Indian population. J Orthodont Sci. 2013; 2: 23-7.

16. Naseh R, Padisar P, ZareNemati P, Moradi M, Shojaeefard B. Comparison of tooth size discrepancy in $\mathrm{Cl}$ II Malocclusion patients with normal occlusions. J Dent (Shiraz). 2012; 13: 151-155.

17. Endo T, Abe R, Kuroki H, Oka K, Shimooka S. Tooth Size Discrepancies among Different Malocclusions in a Japanese Orthodontic Population. Angle Orthod. 2008; 78: 994-9.

18. Uysal T, Sair Z, Basciftci FA, Memili B. Intermaxilary tooth size discrepancy and maloclusion: Is there a relation? Angle Orthod. 2005; 75: 208-13.

19. Santoro M, Ayoub ME, Pardi VA, Cangialosi TJ. Mesiodistal crown dimensions and tooth size discrepancy of the permanent dentition of Dominican americans. Angle Orthod. 2000; 70: 303-7.

20. Manopatanakul S, Watanawirun N. Comprehensive intermaxillary tooth width proportion of Bangkok residents. Braz Oral Res. 2011; 11:67-70.

21. Houston, WJB. The analysis of errors in orthodontic measurements. Am J Orthod. 1983: 83: 382-90.

22. Bolton WA. The clinical application of a tooth-size analysis. Am J Orthod. 1962; 48: 504-29.

23. Heusdens M, Dermaut L, VerbeeckR. The effect of tooth size discrepancy on occlusion: an experimental study. Am J Orthod Dentofacial Orthop. 2000; 117: 184-91.

24. Fattahi HR, Pakshir HR, Hedayati Z. Comparison of tooth size discrepancies among different malocclusion groups. Eur J Orthod. 2006; 28: 491-5.

25. Endo T, Uchikura K, Ishida K, Shundo I, Sakaeda K, Shimooka S. Thresholds for clinically significant tooth-size discrepancy. Angle Orthod. 2009; 79: 740-6;

26. Paredes V, Gandia JL, Cibrian R. Determination of Bolton toothsize ratios by digitization and comparison with the traditional method. Eur $\mathrm{J}$ Orthod. 2006; 28: 120-5.

27. Garn SM, Lewis AB, Kerewsky RS. Sex difference in tooth size. J Dent Res. 1964; 43: 306.

28. Smith SS, Buschang $\mathrm{PH}$, Watanabe E. Interarch tooth size relationships of 3 populations: does Bolton's analysis apply? Am J Orthod Dentofacial Orthop. 2000; 117: 169-74.

29. Bishara SE, Jakobsen JR, Treder JE, Stasi MJ. Changes in the maxillary and mandibular tooth size-arch length relationship from early adolescent to early adulthood. Am J Orthod Dentofacial Orthop. 1989; 95: 46-59.

30. Oktay H, Ulukaya E. Intermaxillary tooth size discrepancies among different malocclusion groups. Eur J Orthod. 2010; 32: 307-12. 